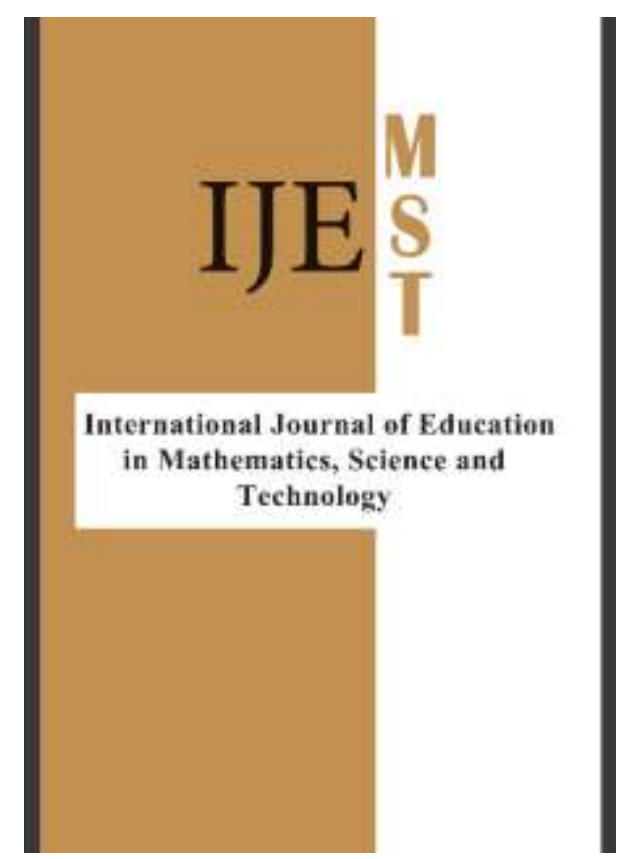

ISSN: $2147-611 \mathrm{X}$
International Journal of Education

in Mathematics, Science and

Technology (IJEMST)

www.ijemst.com

Examination of the Conversations in a

WhatsApp Group Created for

Communication in a Bachelor's Level Astronomy Course

Hafife Bozdemir Yuzbasioglu ${ }^{1}$, Sevcan Candan Helvaci ${ }^{1}$, Ebru Ezberci Cevik ${ }^{2}$, Mehmet Altan Kurnaz ${ }^{1}$

${ }^{1}$ Kastamonu University, Turkey

${ }^{2}$ Erciyes University, Turkey

To cite this article:

Bozdemir Yuzbasioglu, H., Candan Helvaci, S., Ezberci Cevik, E., \& Kurnaz, M. A. (2020). Examination of the conversations in a WhatsApp group created for communication in a bachelor's level astronomy course. International Journal of Education in Mathematics, Science and Technology (IJEMST), 8(2), 168-176.

This article may be used for research, teaching, and private study purposes.

Any substantial or systematic reproduction, redistribution, reselling, loan, sub-licensing, systematic supply, or distribution in any form to anyone is expressly forbidden.

Authors alone are responsible for the contents of their articles. The journal owns the copyright of the articles.

The publisher shall not be liable for any loss, actions, claims, proceedings, demand, or costs or damages whatsoever or howsoever caused arising directly or indirectly in connection with or arising out of the use of the research material. 


\title{
Examination of the Conversations in a WhatsApp Group Created for Communication in a Bachelor's Level Astronomy Course
}

\author{
Hafife Bozdemir Yuzbasioglu, Sevcan Candan Helvaci, Ebru Ezberci Cevik, Mehmet Altan Kurnaz
}

\begin{tabular}{|c|c|}
\hline Article Info & Abstract \\
\hline Article History & \multirow{8}{*}{$\begin{array}{l}\text { The aim of this research on an astronomy course is to examine the situations } \\
\text { that arose when WhatsApp, a social media application, was used as a tool for } \\
\text { cooperation and interaction. In this work, a case study design was adopted. } \\
\text { The WhatsApp group created for the research was composed of } 87 \\
\text { participants and the messages exchanged in the WhatsApp group were used as } \\
\text { research documents. Data were analyzed through descriptive and content } \\
\text { analysis methods. The sharing in the WhatsApp group and the topics of the } \\
\text { messages were revealed in the content analysis. The research results showed } \\
\text { that the students used the WhatsApp group as an interaction tool in an } \\
\text { extracurricular environment. It was also determined that they used this } \\
\text { platform in order to inform each other about daily events and share and } \\
\text { discuss information. }\end{array}$} \\
\hline $\begin{array}{l}\text { Received: } \\
\text { 24 February } 2019\end{array}$ & \\
\hline $\begin{array}{l}\text { Accepted: } \\
22 \text { December } 2019\end{array}$ & \\
\hline Keywords & \\
\hline Astronomy education & \\
\hline WhatsApp & \\
\hline & \\
\hline $\begin{array}{l}\text { Technology supported } \\
\text { education }\end{array}$ & \\
\hline
\end{tabular}

\section{Introduction}

In today's information age, the flashiest and the most important tools that we have are communication technologies (Unal, 2009). Communication technologies, and particularly the Internet, have increasingly found a place in everyday life and have become the most frequently used form of communication media (Kaplan \& Haenlein, 2010; Otrar \& Argin, 2014). The Internet, which allows for a wide variety of information-sharing, became more widespread with Web 2.0 devices. Web 2.0 offers a more interactive web experience for Internet users, and a variety of new applications have emerged, as well (D’Souza, 2006; Otrar \& Argin, 2014).

The use of the Internet as a basis for the integration of technology in education and to support different levels of education is spreading across the world. The Internet helps in developing students' knowledge and skills (Richard \& Haya, 2009). In particular, with improvements in digital media technology, it can be said that the use of the Internet has become more widespread. According to Bouhnik and Deshen (2014), the use of digital media in communication between teachers and students has increased in recent years. Therefore, according to Calvo, Arbioland, and Iglesias (2014), the number of studies investigating the potential impact of digital communication channels has also increased. In these studies, the effects of the use of social media have been indicated, which is rapidly increasing in popularity (e.g., Amry, 2014; Alghazo \& Nash, 2017; Bansal \& Dhananjaj, 2014). Social media applications have diversified and include blogs (e.g., Blogger), microblogs (e.g., Twitter, Tumblr), wikis (e.g., Wikipedia), social bookmarking services (e.g., Instapaper), media-sharing sites (e.g., YouTube, Flickr, Snapchat), podcasts, virtual worlds (e.g., Second Life), social networks (e.g., Facebook, Myspace, FriendFeed, Instagram), and written and voice communication mobile applications (e.g., WhatsApp) (Akar, 2010; Otrar \& Argin, 2014).

For learning on the basis of social media applications, mobile applications are also used. Towards the upper grade levels, the use of mobile phones and other devices and tools becomes especially more frequent (Prensky, 2001). During these processes in which communication becomes easier, exam dates, messages between teachers and/or students, and information-sharing in general is made possible. The transfer of data for educational purposes using mobile technologies is called mobile learning (m-learning), and m-learning can be seen as a next-generation distance education method that provides opportunities wherever and whenever students want to learn. In m-learning, mobile devices and applications are frequently used. An environment can be provided by the use of applications such as WhatsApp and Facebook to support students' learning skills (İşman \& Albayrak, 
2014; Öztürk \& Akgün, 2012). The current study focuses on the WhatsApp application, which was used to supporting learning activities in an extracurricular environment.

WhatsApp is one of the popular mobile applications used for information-sharing between groups and/or individuals through messages including texts, audio files, and video files (Bouhnik \& Deshen, 2014). It is a smartphone application that is especially used by students towards the upper grade levels and can be used with many devices and operating systems, providing and improving opportunities to share their performances and what they have learned (Sayan, 2016). As a tool for learning, the WhatsApp application can be a solution for transferring instant communications between students and teachers within extracurricular environments. By means of WhatsApp, the purpose of which is to facilitate communication, educational materials including chats, voice messages, videos, or photos can easily be shared. In other words, an important advantage can be gained in terms of active learning. Although there is the possibility of distraction (Tindell \& Bohlander, 2012), studies have emphasized the positive effects of using this application on students' motivation and their classroom attendance (e.g., Amry, 2014; Bere, 2012; Rambe \& Chipunza, 2013). In their research about using WhatsApp, for example, Rambe and Bere (2013) showed that the integration of WhatsApp was useful as it increased the interaction between students and made the classroom environment more attractive. Similarly, Plana, Gimeno, Appel, and Hopkins (2015) conducted a study on the effects of using WhatsApp with a group of students learning a foreign language and they concluded that when WhatsApp was used the students became more willing and more motivated. In another study in which the application was used to increase the success of teacher candidates, it was also stated that using WhatsApp facilitated the students' learning while helping them achieve the targeted goals of the lesson (Sayan, 2016).

The positive effects of any carefully thought-out step on learning can be recognized, and we can think about studies of technology integration similarly, together with the use of WhatsApp, one of the examples of the advancing mobile learning environment. Thus, examples of the use of the WhatsApp application should especially focus on the education of teacher candidates, who should have communication skills in higher education where the required devices are used in order to establish a mobile learning environment. Moreover, technological tools, and especially mobile phones, have become indispensable in contemporary society for individuals of all ages. In a study conducted by Sobaih et al. (2016), it was found that WhatsApp and LinkedIn were among the most frequently used social media platforms by faculty members. Moran et al. (2012) also claimed that these are suitable social media tools for teaching purposes. In light of such works, WhatsApp is explored as a social media application in this study.

In the present research, it was aimed to examine the results of using WhatsApp, a social media application that is steadily growing more important in the lives of teacher candidates, as a part of an astronomy course, in which it was used as a tool for cooperation and interaction. With this aim, the research question was posed as follows: What happens when candidate teachers use WhatsApp, a social media application, as a tool for collaboration and interaction in education?

\section{Method}

\section{Research Design}

This research is structured on the basis of a qualitative approach and a case study design was used. Case studies, in which a particular person, group, situation, etc. is studied in depth with great detail, allow the researcher to examine data related to several variables (Fraenkel \& Wallen, 2006). In this study, an exploratory case study approach is used. This type of case study is used to research conditions in which no clear single set of results exists (Yin, 2003; Luo, 2011). Exploratory case studies explore the researcher's point of interest in a case and use multiple sources of data to examine phenomena in their natural contexts (Yin, 1992). The ability to evaluate the content of phenomena, series of activities, and important and different participants is the strength of this approach (Hoffman \& Radojevich-Kelley, 2012). The nature of the present research questions thus led to an exploratory case study.

The research was conducted in an astronomy course in a university in the western Black Sea region of Turkey. A WhatsApp group was created for a period of six weeks for teacher candidates in the field of science education, who were enrolled in the mentioned astronomy course. During this process, the teacher candidates conducted telescope observations for two hours a week in class and one hour a week at night in an extracurricular environment. For this reason, a case study was used here. The case focused on in this study is 
considered to be important for future studies, as analyzing the state of the telescope observations through the use of social media will reveal the importance of benefiting from social media for future researchers.

\section{Study Group}

The WhatsApp group comprised 87 participants, including 4 researchers and 83 teacher candidates. A purposive sampling method was used in this study. The teacher candidates were selected because they took the astronomy course in their fourth year of the degree program. In the 2015-2016 academic year, the astronomy course in the Department of Science Education was offered in the fourth year of education in Turkey. These teacher candidates were considered as a relevant sample because of their active use of social media, and particularly WhatsApp. They stated that they frequently used this application in daily life, and they all participated in the study voluntarily. The participants shared their achievements in the lessons, extracurricular observations, and information from the Internet and other sources in this WhatsApp group, and they also discussed the topics that they did not understand. During this process, the researchers sometimes played the role of initiators of discussions by asking questions, or they functioned as supporters of student participation regarding the topics shared within the group. They did not intervene in conversations among students except for these situations stated here.

\section{Data Collection and Analysis}

In the WhatsApp group, which included both researchers and teacher candidates, the students shared information, asked questions, and had discussions. In addition, they also exchanged visual materials and shared links. The contents of the texts in the WhatsApp group were thus used as documents in this research and were examined with descriptive and content analysis methods.

In this process, first, all of the WhatsApp conversations were taken as text output. A total of 640 texts of the students were included in the analysis, stemming from 20 discussions. Moreover, 98 questions that were asked during the process were examined, as well as the links and visual materials that they had shared. In the descriptive analysis, the shared contents were divided over six weeks, and every week contents were defined by frequency according to the number of participating students and researchers, the number of conversations, the questions of the researchers and students, and expressions of emotion. Moreover, by content analysis, the questions, links, visual materials, and other shared materials were examined and categories were presented. The contributions of the conversations and the aim of the WhatsApp application were also explained. The real names of the participants are not used here; to refer to students, 'S1, S2, ..' codes are utilized in the findings. The researchers are meanwhile identified by the ' $\mathrm{R}$ ' code.

The most well-known strategy for ensuring credibility is triangulation. For this purpose, research triangles were applied. All of the researchers took part in the data collection and analysis processes. In the analysis phase, the researchers first completed the analyses separately, and then they came together with the aim of reaching a consensus. In this way, external reliability was sought. External validity was additionally provided by explaining the characteristics of the study group, specifying the selection of the group, and describing the process.

In order to prevent misunderstandings of some subjective assumptions or data that the researchers may have had regarding the obtained speech texts, participant confirmation was received. A confirmation mechanism created for data sources can help to understand the extent to which the results are sufficient to represent the truth. In this way, factors that threaten internal validity were controlled. In order to show the validity of the study, the findings furthermore generally included the statements of the participants rather than merely the opinions of the researchers.

\section{Results}

The findings from the conversations that took place every week, in terms of expressions of emotion, the number of the students and researchers, the number of conversations, and the number of questions among the students and researchers in the WhatsApp group, were examined and are given in Figure 1. 


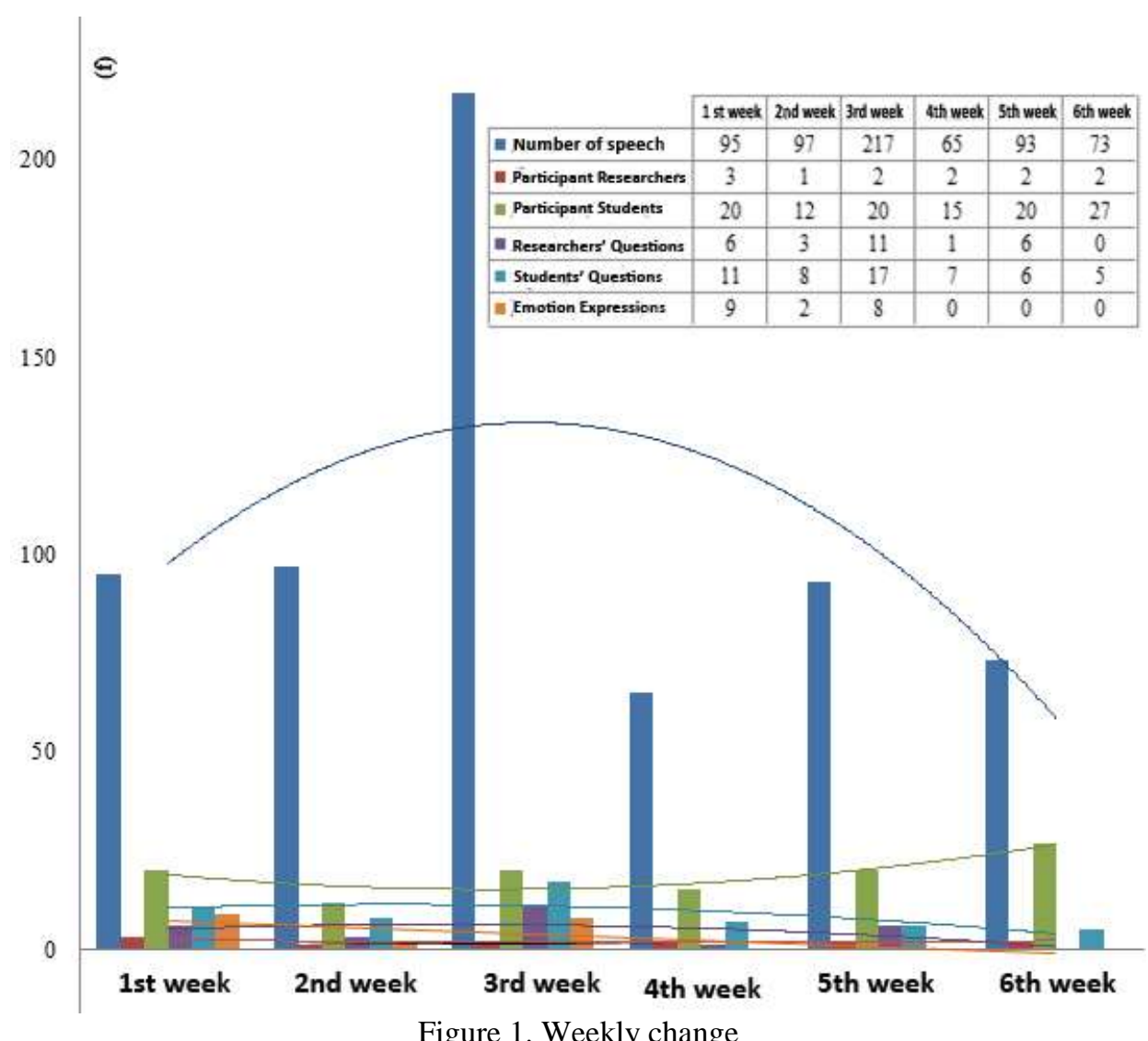

Figure 1. Weekly change

When we look at Figure 1, which presents the results over the 6 weeks of the study, the peak point of conversations (i.e. communications established on WhatsApp) forms the peak of an inverse parabola between the third and the fourth week. In this communication process, it can be seen that the researchers participated in a low but stable number, while the change in the number of participating students also took the shape of an inverse parabola between the third and fourth weeks. During the communication process, the peak of the researchers' questions also took on the shape of an inverse parabola between the third and fourth weeks, while the peak of the students' questions formed an inverse parabola in the second week and the expressions of emotions aimed at communication can be seen to have stopped after the third week. The weekly topics of communication among the researchers and students are listed in Table 1.

Among the subject headings given in Table 1, it can be seen that the topics of communication became clearer after the week in which the researchers and students communicated via WhatsApp most intensely (i.e. third week). In fact, the researchers focused on "application process" and "course content" until the third week, and after the third week they focused mainly on "course content". The findings showed that the students mostly shared messages related to course content after the second week. It is noteworthy that in the third week, and especially in connection with the increase in the number of researchers and the increase in the number of student questions, the number of conversations increased as well. During these student conversations, discussion forums were also noted. The numbers of student questions also increased in these discussion forums:

S1: Venus is a special planet in our solar system. It moves in the opposite direction of the other planets. The axis is 98 degrees. Sometimes this happens to the slope to become parallel to the orbit plane. The information is completely correct.

S2: I think it might be true. The world also has six months of daylight and six months of night. The formation of day and night is related to latitude. So, because it is flattened from the poles, an elliptical sphere and linear velocity are effective for night and day. Then I think this may be true.

$\mathrm{S} 1$ : Uranus * the situation you talk about is very different from Uranus's slope. The information is correct but not relevant to this topic.

S2: I tried to obtain the information by looking at [other] information. I was talking about the Earth in my comment ... Is the comment I made correct?

S1: The information you provided is accurate but not valid for Uranus. You are beginning to get to the truth of the information but are wrong here. Therefore, this can cause major conceptual confusion, like information pollution. There is no interest in concepts such as linear velocity/elliptical sphere, where you 
mention the dark/light side of Uranus. Your thought system may work for other planets in the solar system, but not Uranus.

Table 1. Weekly topics of conversation in the WhatsApp group

\begin{tabular}{|c|c|c|c|}
\hline \multirow{2}{*}{ Week } & \multirow{2}{*}{ Person* } & \multicolumn{2}{|l|}{ Topic } \\
\hline & & Related to content & Related to application process \\
\hline \multirow[b]{2}{*}{1} & $\mathrm{~S}$ & $\begin{array}{l}\text { Planets and astronomical events, Star of } \\
\text { David }\end{array}$ & $\begin{array}{l}\text { Programs like SKView and Night } \\
\text { Sky introduced in the lesson }\end{array}$ \\
\hline & $\mathrm{R}$ & e & $\begin{array}{l}\text { Preparatory studies for telescope } \\
\text { observations, information on } \\
\text { observations, SKView and Night Sky } \\
\text { programs }\end{array}$ \\
\hline \multirow[t]{2}{*}{2} & $\mathrm{~S}$ & $\begin{array}{l}\text { Information about Hubble space telescope, } \\
\text { eclipse of the Sun, lunar eclipse, nebula, star } \\
\text { clusters/ constellations, Jupiter, Leo star } \\
\text { cluster }\end{array}$ & $\begin{array}{l}\text { Hubble space telescope within } \\
\text { SKView program, smartphone } \\
\text { applications (other than those } \\
\text { introduced in the lesson), star clusters } \\
\text { and planet views seen in the } \\
\text { smartphone applications }\end{array}$ \\
\hline & $\mathrm{R}$ & Information about Hubble space telescope & $\begin{array}{l}\text { Video links about eclipse of the Sun, } \\
\text { telescope observations of Jupiter, } \\
\text { WhatsApp usage }\end{array}$ \\
\hline
\end{tabular}

Space tourism, information-sharing by the researchers about Uranus, discussion on astronomy/astrology, location/movement of stars, Polaris, gravitation, phases of the

S moon, nuclear explosions on the Sun, black hole, Sculptor Galaxy, black hole, asteroid, meteor, gravitational waves (news read, current events), Milky Way Galaxy, birth and death of stars

3

Gravitation, discussion
astronomy/astrology, phases of the moon,
35P/Herschel-Rigollet comet, gravitational
waves

Phases of the moon, supernova, nebula, black hole, neutron star, pulsar, dried lake bed on Pluto and dwarf planet (Ceres), 4 S Charon the satellite of Pluto, brown dwarf, KPSS (Turkish Public Personnel Selection

Screenshots from smartphone applications (Saturn, Mars, Scorpius Constellation)

Photo-sharing from moon
observations, encouragement to
question the truth of gathered
information, suggestion to follow
NASA's social media accounts

Screenshots from smartphone applications (Venus) Examination), field examination sharing

\begin{tabular}{|c|c|c|c|}
\hline & $\mathrm{R}$ & Supernova & - \\
\hline \multirow[t]{2}{*}{5} & $\mathrm{~S}$ & $\begin{array}{l}\text { Meteor strike on Jupiter, frozen lake bed on } \\
\text { Pluto, brightness of the stars, phases of the } \\
\text { Moon, starburst, Halley's comet, white } \\
\text { dwarf, black dwarf, neutron stars }\end{array}$ & - \\
\hline & $\mathrm{R}$ & Halley's comet & - \\
\hline \multirow{2}{*}{6} & $\mathrm{~S}$ & $\begin{array}{l}\text { Enlarging of the universe, Andromeda and } \\
\text { Milky Way Galaxies, star bursts }\end{array}$ & $\begin{array}{l}\text { Questions related to telescope } \\
\text { observations }\end{array}$ \\
\hline & $\mathrm{R}$ & e & $\begin{array}{l}\text { Telescope observation plans and } \\
\text { announcement }\end{array}$ \\
\hline
\end{tabular}

*R: Researchers; S: Students.

An important finding that emerged after the third week of student participation was that emotional expressions were no longer shared. In other words, emotional expressions were preferred in the first weeks, but in later weeks, the researchers were more heavily encouraging the use of some smartphone applications that include telescope observations and are used in sky observations. In this regard, an example dialogue is given below:

$\mathrm{S} 1$ : Where is this place?

$\mathrm{R}$ : We are at the observation center with our telescope.

S2: It's super. 
S3: Good luck on the Motherland and People (-)

S4: Fun 8

S5: Yes

S6: When will our class go?

S7: Very exciting.

In the third week, the emotional expressions increased after the sharing of photographs of the surface of the moon taken by the researchers with telescopes. An example dialogue follows:

$\mathrm{R}$ : [A photo of the moon's surface was shown.]

S1: Is this image from the Skyview program, Sir?

$\mathrm{R}$ : We did it, friends. The picture has been taken at that moment.

S2: We also want to see it? (-) It's very exciting.

S3: I want to see it now too.

The students had the opportunity to share the subject/concepts of the astronomy course or links, images, and information related to the subject/concepts outside of the learning environment. A shared image is shown in Figure 2.

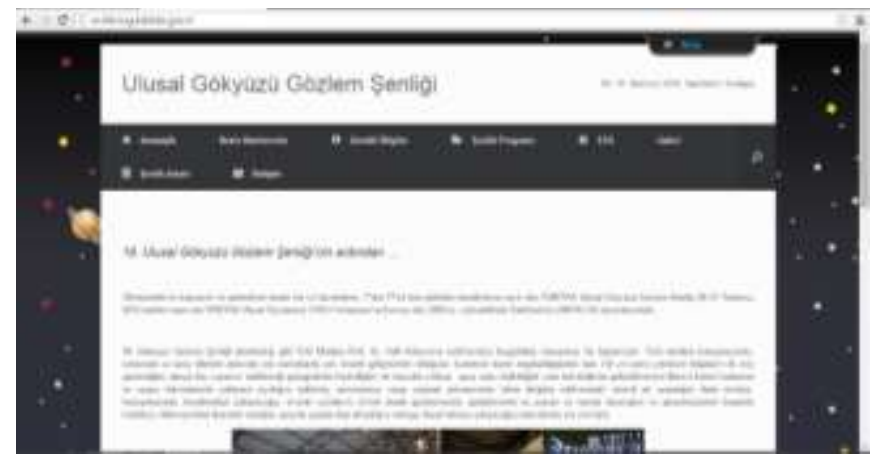

Figure 2. Sharing related to the national sky observation event

As seen in Figure 2, the students made an announcement about sky observation through a link in the group, which is an example of group sharing. One example of information-sharing is a dialogue during the use of the Skyview program, which was introduced in class, as follows:

R: [A photo from Skyview program was shown.]

S1: Is it a telescope in space?

S2: The Hubble Space Telescope is a space telescope sent from Earth to conduct research in space. The Hubble Space Telescope was sent to space in April of 1990. The telescope was sent out to the orbit around the Earth by the Discovery spacecraft. The name of this space telescope was given in memory of the American astronaut Edwin Hubble. The Hubble Space Telescope, also called HUT, is the most important telescope due to its functions and its success, although it is not the first telescope sent to space. HUT is still the largest space telescope.

In the dialogue above, an interesting image overlaps with shared information on this subject from another student as the result of testing the application introduced in the lesson. Based on this sharing, the students viewed the WhatsApp group as a source of information. An example dialogue is as follows:

S1: I wish the information were in Turkish.

S2: [Well, that's how it is, and] we have to use the program. We have a group for the points which we cannot translate.

Via the WhatsApp group discussions, information-sharing is facilitated, as well as instant feedback regarding the mistakes made during these moments of information-sharing. The following dialogue is an example:

$\mathrm{S}$ : [Shared a false photo related to the solar system.]

$\mathrm{R}$ : The model in the picture you shared is not correct ...

S: My heavily shared picture has caught my attention.

$\mathrm{R}:$ Is it true?

S: I do not know; Sir, can you give the information about how this is wrong?

$\mathrm{R}$ : The sizes of celestial bodies.... 
Another use of this social media tool involved the sharing of current events related to astronomy. An example of this is given below:

S: Good afternoon friends, you can watch the solar eclipse live at 03.57 tonight at http://www.nasa.gov/multimedia/nasatv/index.html. Observations cannot be made from our country. The next solar eclipse will take place on June 21,2020, and we will be able to watch this one as a partial solar eclipse if it's an annular eclipse. Likewise, this month the lunar eclipse will be on March 23. This eclipse will take place at 14.02 . You can also watch this eclipse through the same link.

The WhatsApp group messages also set the stage for learning and talking about new topics and concepts. In the discussions of astronomy and astrology, the issues of mass gravity and the movement of stars were the main topics of conversation. Such discussions also set the stage for discussions on new topics and concepts. A sample dialogue is given below:

S1: I have to point out that when you search for astronomy on Google, a great majority of the search results are related to "astrology." I am sorry to say for those friends who believe: There is no science called astrology. The signs, rising, all the information such as "Jupiter is in your zone" are all lies. The star positions in the moment of a person's birth (somehow they have not changed at all since astrology was introduced) and the star positions in other moments have no effect on the human being. To give a simple example, the closest star to the Earth is Alpha Centauri, and the distance from us is 4.37 light years. So we can notice the change in this star only after 4.37 years. As a result, do not believe in the lie of astrology, and if you see a site in this regard when you search, do not rely on the information it contains.

S2: Does our position to stars not change with the simplicity of the Earth's turning, if even the position of stars etc. does not change? In other words, do the spheres of influence not change? I wondered when it was ever said that a science called astrology did not exist.

S1: The position of the stars does not change in the astrological maps that I am talking about. In fact, the position of all of them is changing except for a few stars. A few stars are also moving, but the speed of movement is the same as the Earth's speed, so they always center around the same position: for example, Polaris. In other words, the movements, the positions of the stars have no effect on the behavior, personality of any living creature on Earth.

R: I do not agree... If there is gravitation, and it is there and the people who are also masses influenced by positions of the celestial bodies in relation to each other... But there is no science that informs people about their future based on the positions and movements of the celestial bodies.

S1: The gravitational force is the greatest force we know in our universe. There is an effect on our planet and implicitly on all living creatures on the planet. But what I would like to talk about here is that this or those forces cannot influence our spiritual behaviors, our business life, or decisions we make about our lives. The position of the stars does not have a spiritual effect on our lives in this way and we cannot know what will happen in the future by looking at them. Astrology claims that it can know how we will behave and what decisions we should make according to the stars' positions. I say that these claims are completely unreal.

As we see in the dialogue above, the researcher also participated in the discussion on astronomy and astrology that the students had started. During the information-sharing and the discussion on this subject, new ideas/concepts within the scope of astronomy were also expressed along with justification for the given information and different thoughts. When the WhatsApp discussions were examined, it was understood that while the students were preparing for the astronomy exam while utilizing the application, they had access to the concepts, their previous associations, and instant answers to their questions before the exam. An example dialogue is given below:

S1: I'm sorry friends. It was late at the time :( Now when I was looking at the notes, something got me obsessed. The white dwarf star is in the process of death, the temperature of the star is max, so it's turning white. Then the luminescence is over and it enters the black dwarf period. Now we see the stars as white in general; are they all white dwarfs?

S2: Absolutely not. When we look with the naked eye, we see all the stars as white. The reason for this is that the human eye is so limited that it cannot choose true colors at night.

\section{Conclusions, Discussion, and Recommendations}

In this study, an investigation has been performed regarding which situations might emerge when teacher candidates use social media applications like WhatsApp as the instrument of communication in accordance with the requirements of a course on astronomy within a faculty of education. The findings can be summarized as 
follows: the number of researchers participating was distributed in a balanced manner according to weeks, emotional expressions were not shared after the third week, the third week represented the peak of the participants' conversations and question numbers in the shape of an inverse parabola, and the third week saw the lowest point of the number of questions of participating students and researchers, forming a parabola.

When the findings were interpreted, it became clear that participants should be encouraged to participate if WhatsApp is used for classes and the participants tended towards course-oriented sharing for at least two weeks. When Figure 1 is examined, it is seen that after the third week, the participants directly shifted towards courseoriented sharing by abandoning the emotional expressions they used in other social networking environments. Beginning with the third week, it was also seen that the number of participants increased, albeit slightly, when the total number of conversations and the number of participants were compared. In that case, it can be said that the tendency of the participants to take part in the WhatsApp conversations was increasing as long as there was a focus on the discourse/sharing of lessons. From this point of view, it can be suggested that teachers and researchers who use WhatsApp in classes should allow at least two weeks for the participants to acclimate to the idea of using this new environment for lessons. Practice also showed that the participants' questions were increased in terms of the number of conversations in the first weeks. This can also be interpreted in reverse: as the number of participants' conversations increases, the number of questions also increases. In that case, participants should be encouraged to talk in this social environment, and this can be done by the researchers directly asking for the opinions of the reluctant participants, if any.

When the findings of the subject content of the communication between the participants during the implementation process were analyzed (see Table 1), it was seen that there were two types of sharing, namely the sharing of information about the application process and about the subject contents of the sharing. As the weeks progressed, it can be said that the sharing about subject contents increased. However, the results of this study cannot be generalized and further studies can be proposed in the subject area. It has been found that the students used the WhatsApp group as a complementary tool to interact with their friends outside of class, inform each other about current astronomical events, share important information they had gained, and examine the information obtained from either the astronomy course or other sources. During this process of sharing, the participants had the opportunity to get instant feedback from both friends and researchers. In addition, the researchers used sharing among the group to draw attention to topics, stimulate curiosity, and motivate the class.

In other studies (e.g., Amry, 2014; Bere, 2012; Plana et al, 2015; Rambe \& Bere, 2013; Rambe \& Chipunza, 2013), it was emphasized that the use of WhatsApp increases students' motivation, centers their attention, and provides better interaction. The WhatsApp group in the present case study provided information to the researchers on how much interest the contents taught within the course drew, as well as how well the contents were learned. It can be argued that using WhatsApp is a supportive option for improving learning; this feature of WhatsApp was also noted in a study by Sayan (2016). It is thus seen that technology has been included in teaching environments and the WhatsApp application can be used as an effective tool in gaining the aforementioned benefits. It has been determined that WhatsApp group applications can be used to support communications in a course, can serve as a tool for the transfer of course contents to extracurricular environments, and are recommended by all stakeholders. In this study, the WhatsApp application was utilized for astronomy topics because of the nature of the selected course. Such applications can certainly be used for other subject matters related to daily life as well.

\section{Notes}

The parts of this study were presented in the 12. National Congress on Education in Science and Mathematics, Trabzon, Turkey.

\section{References}

Akar, E. (2010). Sosyal medya pazarlaması: Sosyal web'de pazarlama stratejileri [Social media marketing: Social web marketing strategies]. Ankara: Elif Yayınevi [Elif Publishing House].

Alghazo, Y. M., \& Nash, J. A. (2017). The effect of social media usage on course achievement and behavior. Journal of Education and Practice, 8(2), 161-167.

Amry, A. B. (2014). The impact of WhatsApp mobile social learning on the achievement and attitudes of female students compared with face to face learning in the classroom. European Scientific Journal, 10(22), 116136. 
Bansal, T,. \& Joshi, D. (2014). A study of students experiences of WhatsApp mobile learning. Global Journal of Human-Social Science Research, 14(4), 26-33.

Bere, A. (2012). A comparative study of student experiences of ubiquitous learning via mobile devices and learner management systems at a South African University. Proceedings of the 14th Annual Conference on World Wide Web Applications Durban.

Bouhnik, D., \& Deshen, M. (2014). WhatsApp goes to school: Mobile instant messaging between teachers and students. Journal of Information Technology Education: Research, 13, 217-231.

Calvo, R., Arbiol, A., \& Iglesias, A. (2014). Are all chats suitable for learning purposes? A study of the required characteristics. Procedia Computer Science, 27, 251-260.

D'Souza, Q. (2006). Web 2.0 ideas for educators a guide to RSS and more, version 2.0. Retrieved from http://www.teachinghacks.com/audio/100ideasWeb2educators.pdf.

Fraenkel, J. K., \& Wallen, N. E. (2006). How to design and evaluate research in education (6th ed.). New York: McGraw-Hill, Inc.

Hoffman, D. L., \& Rodajevich-Kelley, N. (2012). Analysis of accelerator companies: An exploratory case study of their programs, processes, and early results. Small Business Institute Journal, 8(2), 54-70.

Kaplan, A.M., \& Haenlein M. (2010). Users of the world, unite. The challenges and opportunities of social media. Business Horizons, 53(1), 59-68.

Isman, A., \& Albayrak, E. (2014). Ağlardan facebook'un eğitime yönelik etkililiği [Effectiveness of facebook as a social network in education]. Trakya University Journal of Education, 4(1), 129-138.

Moran, M., Seaman, J., \& Tinti-Kane, H. (2012). Blogs, Wikis, Broadcast, Facebook: How today's higher education faculty use social media. The Babson Survey Research Group, and Conversion. Research report published by Pearson.

Otrar, M., \& Argin, F.S. (2014). An Examination of students' attitudes towards social media in the context of usage habits. Journal of Education and Training Researches, 3(3), 1-13.

Öztürk, M ve Akgün, Ö. E. (2012). Üniversite öğrencilerinin sosyal paylaşım sitelerini kullanma amaçları, bu sitelerin olumlu-olumsuz etkileri ve eğitimlerinde kullanılması ile ilgili görüşleri. [University students' purposes in using social networking sites, and their opinions on using these sites in education]. Sakarya University Journal of Education, 2(3), 49-67.

Plana, M. G. C., Gimeno, A., Appel, C., \& Hopkins, J. (2015). Improving learners' reading skills through 1nstant short messages: a sample study using WhatsApp. 4th WorldCALL Conference, 10-13 July 2013, Glasgow.

Prensky, M. (2001). Digital natives, digital immigrants. On the Horizon, 9(5), 1-6.

Rambe, P., \& Bere, A. (2013). Using mobile instant messaging to leverage learner participation and transform pedagogy at a South African University of Technology. British Journal of Educational Technology, 44(4), 544-561.

Rambe, P., \& Chipunza, C. (2013). Using mobile devices to leverage student access to collaborativelygenerated resources: a case of WhatsApp instant messaging at a South African University. In International Conference on Advanced Information and Communication Technology for Education ICAICTE.

Sayan, H. (2016). Affecting higher students learning activity by using WhatsApp. European Journal of Research and Reflection in Educational Sciences, 4(3), 88-93.

Sobaih, A. E. E., Moustafa, M. A., Ghandforoush, P., \& Khan, M. (2016). To use or not to use? Social media in higher education in developing countries. Computers in Human Behavior, 58, 296- 305.

Tindell, D. R., \& Bohlander, R. W. (2012). The use and abuse of cell phones and text messaging in the classroom: A survey of college students. College Teaching, 60(1), 1-9.

Unal, Y. (2009). History of information society. Journal of History School, 5, 123-144.

Yin, R. K. (1992). The case study method as a tool for doing evaluation. Current Sociology 40(1), 121 - 137.

Yin, R. K. (2003). Applications of case study research (2 ${ }^{\text {th }}$ ed.). London: Sage Publications.

\section{Author Information}

Hafife Bozdemir Yuzbasioglu
Kastamonu University
Kastamonu, Turkey
Contact e-mail: hbozdemir@kastamonu.edu.tr

Ebru Ezberci Cevik

Erciyes University

Kayseri, Turkey

\author{
Sevcan Candan Helvaci \\ Kastamonu University \\ Kastamonu, Turkey
}

\author{
Mehmet Altan Kurnaz \\ Kastamonu University \\ Kastamonu, Turkey
}

